\title{
INTERVENSI PEKERJA SOSIAL TERHADAP ORANG DENGAN SKIZOFRENIA
}

\author{
Meilanny Budiarti S, Hetty Krisnani, Ifani Hadrasari \\ meilannybudiarti13@gmail.com; hettykrisnani@yahoo.com; ifanihdrsr@gmail.com;
}

\begin{abstract}
ABSTRAK
Skizofrenia adalah salah satu gangguan jiwa paling berat. Skizofrenia adalah gangguan psikotik yang ditandai dengan gangguan utama dalam pikiran, emosi, dan perilaku-pikiran yang terganggu, dimana berbagai pemikiran tidak biasa dan tidak sesuai; dan berbagai gangguan aktivitas motorik yang bizarre. Skizofrenia membutuhkan intervensi dari berbagai multidisipliner, salah satunya adalah Pekerja Sosial.

Pekerja Sosial bekerja dalam seting generalis, dan bisa memasuki bidang kesehatan jiwa. Intervensi yang dilakukan oleh pekerja sosial akan berbeda dengan profesi lain, meski melalui cara yang sama namun bisa berbeda dalam proses penanganannya. Oleh karena itu, terdapat keterkaitan dengan orang dengan Skizofrenia dengan profesi pekerjaan sosial.
\end{abstract}

Kata kunci: Skizofrenia, cognitive behavior therapy, pekerja sosial

\section{PENDAHULUAN}

Skizofrenia adalah salah satu gangguan psikopatologi paling berat. Skizofrenia adalah gangguan psikotik yang ditandai dengan gangguan utama dalam pikiran, emosi, dan perilaku-pikiran yang terganggu, dimana berbagai pemikiran tidak datar dan tidak sesuai, dan berbagai gangguan aktivitas motorik yang bizarre (Davison dkk. 2012). Pasien Skizofrenia menarik diri dari orang lain dan kenyataan, sering kali masuk ke dalam kehidupan fantasi yang penuh delusi dan halusinasi.

Penyebab pasti skizoprenia tidak diketahui, namun kombinasi genetika, lingkungan, serta struktur dan senyawa kimia pada otak yang berubah mungkin berperan atas terjadinya gangguan. Skizofrenia ditandai dengan pemikiran atau pengalaman yang nampak tidak berhubungan dengan kenyataan, ucapan, dan penurunan partisipasi dalam aktivitas sehari-hari. Kesulitaan dalam berkonsentrasi dan mengingat.

Salah satu jenis dari gangguan jiwa adalah penyakit Skizofrenia. Di beberapa wilayah kecil Indonesia, Skizofrenia masih dianggap sebagai kutukan roh atau dewa, juga dianggap penderita mengalami kerasukan setan. Masih adanya berita pemasungan orang penderita gangguan jiwa di Indonesia memperlihatkan bahwa adanya penderita gangguan jiwa yang belum tertangani oleh stakeholder yang menangani orang dengan masalah kejiwaan.

Fenomena gangguan jiwa juga terdapat di kota-kota besar di Indonesia. Sebuah media harian Suara Merdeka (25-7-1997: hlm 7) menyebutkan bahwa, $19 \%$ dari penduduk kotakota besar di Indonesia seperti Jakarta, Bandung, Semarang, Surabaya, Medan, dan Makassar mengalami gangguan mental (dalam Simanjuntak, 2008). Kota-kota besar menjadi salah satu bagian dari masyarakat yang menderita gangguan jiwa. Menurut data dari World Health Organization (WHO), yang dikutip oleh Albert Maramis (2004), mengungkapkan bahwa sekitar 26 juta jiwa penduduk Indonesia mengidap gangguan jiwa, dan 13,2 juta jiwa diantaranya mengalami depresi (dalam Utomo, 2013). Hal ini membuktikan bahwa Indonesia memiliki orang-orang dengan gangguan kejiwaan pada penduduknya yang berhak untuk mendapatkan intervensi lebih lanjut.

Menurut Hasil Survei Riset Kesehatan Dasar (Riskesdas) tanggal 02 Desember 2013, oleh Badan Penelitian dan Pengembangan Kesehatan (Balitbangkes), Kementerian 
Kesehatan yang dilaksanakan mengungkapkan fakta menarik mengenai prevalensi gangguan jiwa di Indonesia, yaitu 1,7 per mil (dalam Kompasiana, 16-01-14). Hal ini mengartikan 1-2 orang dari 1000 orang penduduk Indonesia mengalami gangguan jiwa terutama gangguan Skizofrenia. Fakta lain dari Hasil Riskesdas Tahun 2013 menunjukkan, prevalensi gangguan jiwa berat atau disebut psikosis/Skizofrenia di daerah pedesaan ternyata lebih tinggi dibanding daerah perkotaan. Di daerah pedesaan, proporsi rumah tangga dengan minimal salah satu anggota rumah tangga mengalami gangguan jiwa berat dan pernah dipasung mencapai $18,2 \%$. Sementara di daerah perkotaan, proporsinya hanya mencapai $10,7 \%$. Hal ini menunjukan akan faktor budaya, ekonomi, dan sosial yang berbeda antara perkotaan dan pedesaan yang menyebabkan adanya tekanan, gejala stres, dan depresi akan mempengaruhi pada kejiwaan seseorang, dan cara orang di sekitarnya memperlakukan orang dengan gangguan jiwa. Gejala Skizofrenia telah ada di daerah pedesaan dan perkotaan di Indonesia, bahkan terdapat fenomena pemasungan terhadap orang dengan Skizofrenia.

Selanjutnya menurut data Kementerian Kesehatan Republik Indonesia (Kemenkes) yang dipublikasikan pada tahun 2014, jumlah penderita skizofrenia di Indonesia diperkirakan mencapai 400 ribu orang. Sedangkan akses terhadap pengobatan dan pelayanan kesehatan jiwa masih belum memadai. Akibatnya, sebagian besar penduduk di negara ini, terutama di pelosokpelosok desa, kerap memperlakukan pasien gangguan jiwa dengan tindakan yang tidak layak seperti pemasungan.

Negara Indonesia memiliki penduduk yang mengalami Skizofrenia dan depresi, dengan adanya fenomena penduduk tersebut Indonesia tentu harus melakukan sesuatu untuk orang-orang termarjinalkan seperti orang dengan Skizofrenia. Keberadaan masyarakat dengan gangguan kejiwaan di Indonesia adalah salah satu fokus yang harus mendapat penanganan demi keberfungsian sosial, sehingga Indonesia tentu harus memahami bagaimana kondisi terkini, proses pelayanan pemulihan yang diberikan, dan pengembalian kepada masyarakat, untuk kembali berfungsi secara sosial. stakeholder yang terdiri dari government, non-government organization, private sector, dan civil society melakukan upaya dalam penanganan orang dengan masalah kejiwaan khususnya Skizofrenia. Stakeholders melakukan upaya dalam penanganan orang dengan masalah kejiwaan khususnya Skizofrenia.

Corrigan (2003) berpendapat bahwa, orang dengan gangguan jiwa membutuhkan persamaan kesempatan untuk berpartisipasi dalam aktifitas kehidupan seperti masyarakat lainnya dengan mental yang sehat (dalam Llyold, 2010). Keberfungsian sosial adalah tujuan upaya pemulihan yang dilakukan oleh berbagai profesi. Salah satu profesi yang bergerak dalam kesehatan jiwa adalah profesi Pekerjaan Sosial. Orang dengan Skizofrenia adalah salah satu kelompok yang berhak mendapatkan upaya kesehatan jiwa dan berfungsi secara sosial. Upaya kesehatan jiwa dengan kuratif dan rehabilitatif adalah salah satu lahan Pekerja Sosial dalam hal mengintervensi atau memberikan treatment kepada orang dengan Skizofrenia sehingga orang dengan Skizofrenia bisa berfungsi secara sosial. Orang-orang yang terkena dampak Skizofrenia adalah salah satunya anggota keluarga mereka yang menunda atau menghindari pengobatan karena takut, stigma, penyangkalan, kepercayaan budaya atau kurangnya informasi yang sederhana. Oleh karena itu, terdapat beberapa praktik yang dilakukan oleh Pekerja Sosial demi membantu orang dengan Skizofrenia memulihkan dirinya yang masih melalui perdebatan dalam proses intervensinya.

Salah satu praktik intervensi yang dapat digunakan oleh pekerja sosial adalah cognitive behavior therapy. Seperti penelitian yang dilakukan oleh Fauziah (2009), cognitive behavior therapy yang dilakukan memberikan dampak peningkatan kemampuan kognitif dan kemampuan perilaku adaptif klien secara bermakna dimana peningkatan kemampuan perilaku adaptif lebih tinggi dibanding 
kemampuan kognitif. Apa perbedaan pekerja sosial dengan psikiater dan profesi medis lainnya? Pekerja sosial adalah profesi yang harus melihat masalah secara keseluruhan, hubungan interaksionis yang ada harus diatasi oleh Pekerja Sosial. Oleh karena itu, dalam artikel ini akan menyebutkan bagaimana cognitive behavior therapy bisa dilakukan oleh Pekerja Sosial dalam intervensi orang dengan Skizofrenia.

\section{TINJAUAN KONSEPTUAL}

\section{Skizofrenia}

Menurut Kamus Lengkap Psikologi (Chaplin, 1989), Skizofrenia adalah sekelompok reaksi psikotis dengan ciri-ciri pengunduran diri dari kehidupan sosial, gangguan emosional, dan afektif yang kadangkala disertai halusinasi dan delusi serta tingkah laku yang negatif/merusak. Skizofrenia menurut DSM-IV-TR (2000) oleh American Psychiatric Association,yaitu:

"Skizofrenia adalah gangguan yang berlangsung selama minimal 6 bulan dan mengalami gejala fase aktif minimal 1 bulan (yaitu, dua [atau lebih] dari: waham [delusi], halusinasi, bicara terdisorganisasi (sering menyimpang), perilaku yang terdisorganisasi, gejala negatif [pedataran afektif, tidak ada kemauan dan terjadinya disfungsi sosial/pekerjaan])."

"Gejala karakteristik Skizofrenia melibatkan berbagai disfungsi kognitif dan emosional yang meliputi persepsi, pemikiran inferensial, bahasa dan komunikasi, pemantauan perilaku, mempengaruhi, kelancaran dan produktivitas berpikir dan berbicara, kapasitas hedonis, kemauan dan tekad, dan perhatian (DSM IV)."

Menurut Kartono (2003), berkaitan dengan Skizofrenia adalah:

"Skizofrenia terjadi dikarenakan terdapat disintegrasi pribadi dan kepecahan pribadi, selalu mencoba melarikan diri dari kenyataan hidup dan berdiam dalam dunia fantasinya, perasaannya selalu tidak tenang, mengalami gangguan intelektual berat, sehingga pikirannya melompat-lompat tanpa arah."

Skizofrenia adalah salah satu gangguan jiwa yang berat, karena memiliki beberapa ciri minimal 2 gejala yang muncul antara gejala positif dan negatif. Meski orang dengan Skizofrenia telah memakan obatobatan, orang dengan Skizofrenia tidak akan sembuh sepenuhnya, dikarenakan bisa saja mereka tetap melihat delusi dan halusinasi yang ada. Melarikan diri dari dunia nyata, berkurangnya kemampuan berkomunikasi dan memilah bahasa, adanya delusi, serta halusinasi, merupakan gejala yang sulit dihilangkan dan ditangani untuk segera pulih dalam menangani gejala yang muncul tersebut. Tidak seperti kriteria diagnosis mental disorders lain, tidak ada simtom penting yang harus ada menegakkan diagnosis Skizofrenia. Oleh karena itu, para pasien Skizofrenia dapat berbeda antara satu dengan lainnya dibanding para pasien gangguan lain (Davison dkk., 2012).

Tiga kategori simtom utama Skizofrenia adalah: positif, negatif, dan disorganisasi, yaitu:

1) Simtom positif mencakup hal-hal yang berlebihan dan distorsi, seperti halusinasi dan waham.

2) Simtom negatif mencakup berbagai defisit behavioral yang merupakan prediktor kuat terhadap kualitas hidup yang rendah, seperti avolition, alogia, anhedonia, afek datar, dan asosialitas (Ho dkk., 1998). Simtom negatif terdiri dari : avolition, alogia, anhedonia, afek datar, dan asosialitas.

3) Simtom Disorganisasi mencakup disorganisasi pembicaraan dan perilaku aneh (bizarre).

Jenis Skizofrenia terdiri dari Skizofrenia Paranoid, tidak terorganisir, 
katatonik, Undifferentiated, dan Residual (DSM-IV-TR).

1) Jenis Paranoid

Fitur penting dari jenis Skizofrenia paranoid ini adalah adanya delusi yang menonjol atau halusinasi pendengaran dalam konteks perluasan mempengaruhi fungsi kognitif. Delusi biasanya berlebihan atau megah, atau keduanya, tapi delusi dengan tema lain (misalnya, cemburu, religiusitas, atau somatisasi) mungkin juga terjadi. Halusinasi juga biasanya terkait dengan delusi. Fitur terkait termasuk kecemasan, kemarahan, sikap acuh tak acuh, dan argumentatif. Hal ini dapat mempengaruhi individu untuk perilaku bunuh diri, dan kombinasi delusi dengan kemarahan dapat mempengaruhi individu untuk kekerasan. Beberapa bukti menunjukkan bahwa, prognosis untuk jenis paranoid mungkin jauh lebih baik daripada yang jenis lain Skizofrenia, terutama yang berkaitan dengan fungsi kerja dan kapasitas untuk hidup mandiri. Suatu jenis paranoid Skizofrenia di mana kriteria sebagai berikut:

a. Keasyikan dengan satu atau lebih dari delusi atau sering halusinasi pendengaran;

b. Tak satu pun menonjol: bicara tidak teratur, tidak teratur atau perilaku katatonik, serta flat atau tidak mempengaruhi.

2) Jenis Tidak Teratur

Fitur penting dari jenis tidak terorganisir dari Skizofrenia adalah bicara tidak teratur, perilaku tidak teratur, dan datar. Bicara tidak teratur dapat disertai dengan kekonyolan dan tawa yang tidak terkait erat dengan isi pembicaraan. Perilaku disorganisasi (yaitu, kurangnya orientasi tujuan) dapat menyebabkan gangguan parah pada kemampuan untuk melakukan aktivitas sehari-hari (misalnya, mandi, berpakaian, atau menyiapkan makanan). Kriteria untuk Jenis katatonik dari Schizophrenia tidak terpenuhi, dan delusi atau halusinasi, jika ada, yang fragmentaris dan tidak diatur dalam tema yang koheren. Fitur terkait termasuk meringis, laku, dan keanehan lainnya dari perilaku. Kinerja gangguan dapat dicatat pada berbagai tes neuropsikologi dan kognitif. Suatu jenis Skizofrenia di mana kriteria sebagai berikut:

a. Semua berikut menonjol: bicara tidak teratur; perilaku tidak teratur; datar atau tidak pantas mempengaruhi,

b. Kriteria tidak terpenuhi untuk katatonik Type.

3) Jenis Katatonik

Fitur penting dari jenis katatonik dari Skizofrenia adalah gangguan psikomotor ditandai yang mungkin melibatkan imobilitas motorik, aktivitas motorik yang berlebihan, negativisme ekstrim, sifat bisu, keanehan gerakan sukarela, echolalia, atau echopraxia. Aktivitas motorik yang berlebihan tampaknya tanpa tujuan dan tidak dipengaruhi oleh rangsangan eksternal. Echolalia adalah patologis, parrotlike, dan pengulangan tampaknya tidak masuk akal dari kata atau frase hanya diucapkan oleh orang lain. Echopraxia adalah imitasi berulang gerakan orang lain. Fitur tambahan termasuk stereotips, dan ketaatan otomatis atau mimikri. Selama pingsan katatonik parah atau kegembiraan, orang mungkin perlu pengawasan hati-hati untuk menghindari menyakiti diri atau merugikan orang lain. Ada potensi risiko kekurangan gizi, kelelahan, hiperpireksia, atau cedera diri ditimbulkan. Suatu jenis Skizofrenia di mana gambaran klinis didominasi oleh setidaknya dua hal berikut:

a. imobilitas motorik yang dibuktikan dengan ayan (termasuk fleksibilitas lilin) atau stupor; 


\begin{tabular}{|c|c|c|c|c|}
\hline $\begin{array}{c}\text { SHARE: SOCIAL WORK } \\
\text { JURNAL }\end{array}$ & VOLUME: 7 & NOMOR: 2 & HALAMAN: $1-79$ & $\begin{array}{l}\text { ISSN:2339 -0042 }(p) \\
\text { ISSN: } 2528-1577(e)\end{array}$ \\
\hline
\end{tabular}

b. aktivitas motorik yang berlebihan (yang tampaknya tanpa tujuan dan tidak dipengaruhi oleh rangsangan eksternal);

c. negativisme yang ekstrim (perlawanan tampaknya tanpa motif untuk semua instruksi atau pemeliharaan postur yang kaku terhadap upaya untuk dipindahkan) atau sifat bisu;

d. keanehan gerakan sukarela yang dibuktikan dengan sikap (asumsi sukarela yang tidak pantas atau aneh postur), gerakan stereotipik, laku menonjol, atau meringis menonjol; serta

e. echolalia atau echopraxia.

4) Jenis Undifferentiated

Fitur penting dari Skizofrenia undifferentiated adalah adanya gejala yang memenuhi Kriteria A dari Skizofrenia tapi yang tidak memenuhi kriteria untuk jenis Paranoid, tidak terorganisir, atau katatonik.

5) Jenis Residual

Tipe residual dari Skizofrenia harus digunakan bila telah ada setidaknya satu episode Skizofrenia, tetapi gambaran klinis saat ini tanpa gejala psikotik positif yang menonjol (misalnya, delusi, halusinasi, bicara tidak teratur atau perilaku). Ada bukti terus gangguan seperti yang ditunjukkan oleh adanya gejala negatif (misalnya, datar mempengaruhi, kemiskinan berbicara, atau avolition) atau dua atau gejala positif lebih dilemahkan (misalnya, perilaku eksentrik, bicara ringan teratur, atau keyakinan aneh). Jika delusi atau halusinasi yang hadir, mereka tidak menonjol dan tidak disertai dengan mempengaruhi kuat. mungkin juga terus menerus hadir selama bertahuntahun, dengan atau tanpa eksaserbasi akut. Suatu jenis Skizofrenia di mana kriteria sebagai berikut:

a. Tidak adanya delusi yang menonjol, halusinasi, bicara tidak teratur, dan perilaku sangat tidak teratur atau katatonik;

b. Ada terus bukti gangguan, seperti yang ditunjukkan oleh adanya gejala negatif atau dua atau lebih gejala kriteria A untuk Skizofrenia, hadir dalam bentuk dilemahkan (misalnya, keyakinan aneh, pengalaman persepsinya)

\section{Pekerja Sosial pada Orang dengan Skizofrenia}

Tahap intervensi orang dengan Skizofrenia tidak melibatkan Pekerja Sosial saja, namun melibatkan multidisiplin lain. Sebagian melibatkan pekerja sosial, baik bekerja secara mandiri maupun bekerjasama dengan tim lintas-disiplin. Sebagaimana diidentifikasi oleh penyalahgunaan zat dan kesehatan mental layanan administrasi (Heller \& Glitterman, 2010), enam program termasuk:

1) Perawatan koordinasi, termasuk tegas komunitas pengobatan (ACT) dan manajemen kasus intensif (MKI),

2) Terintegrasi dual-diagnosis perawatan (IDDT), pendidikan

3) Keluarga dan psiko pendidikan, manajemen mandiri

4) Kesehatan,

5) Mandiri dan layanan dukungan rekan, dan

6) Mendukung pekerjaan.

Program unggulan telah diidentifikasi, dan gerakan pemulihan berfokus pada apa yang orang dengan Skizofrenia lakukan dan mencapai, terlepas dari kesehatan dan tantangan kesehatan mental. Sebagai pekerja social, kita berada di cangkir, dituduh mempromosikan dan mendukung kemungkinan untuk pemulihan, stabilitas, kepemilikan masyarakat dan peningkatan kualitas hidup, tanpa meminimalkan atau menghadap rintangan signifikan terlibat.

Hal-hal yang dapat dilakukan pada orang dengan gangguan jiwa adalah melalui rehabilitasi, sedangkan jenis rehabilitasi terdiri dari: 


\begin{tabular}{|c|c|c|c|c|}
\hline $\begin{array}{c}\text { SHARE: SOCIAL WORK } \\
\text { JURNAL }\end{array}$ & VOLUME: 7 & NOMOR: 2 & HALAMAN: $1-79$ & $\begin{array}{l}\text { ISSN:2339 -0042 }(p) \\
\text { ISSN: } 2528-1577(e)\end{array}$ \\
\hline
\end{tabular}

1) Rehabilitasi Medis, yaitu upaya mengembalikan kemampuan pasien melalu layanan kesehatan, pemberian alat bantu dan terapi fisiologis. Dalam konteks rumah sakit umum dilengkapi layanan psikologis dan pekerja sosial medis. Rumah sakit jiwa layanan psikiater, pekerja sosial dan psikolog.

2) Rehabilitasi pendidikan, yaitu upaya penanaman dan pengembangan potensi intelektual siswa, khususnya setting SLB A (cacat netra), B (cacat rungu), C (cacat mental), D (cacat tubuh).

3) Rehabilitasi vokasional (kekaryaan), yaitu upaya pemberian bekal keterampilan kerja sehingga klien memiliki kesiapan untuk mandiri secara ekonomi di masyarakat.

4) Rehabilitasi sosial yaitu upaya ditujukan untuk mengintegasikan kembali seseorang ke dalam kehidupan masyarakat dengan cara membantunya menyesuaikan diri dengan keluarga, masyarakat dan pekerjaan. Seseorang dapat berintegrasi dengan masyarakat apabila memiliki kemampuan fisik, mental dan sosial serta diberikan kesempatan untuk berpartisipasi.

Menurut T. Sumarnonugroho (1987:43) fungsi-fungsi dari kesejahteraan sosial sebagai berikut:

1) Fungsi penyembuhan dan pemulihan (kuratif/remedial dan rehabilitatif). Bertujuan untuk meniadakan hambatan-hambatan atau masalah sosial yang ada. Fungsi pemulihan (rehabilitatif terutama untuk menanamkan dan menumbuhkan fungsionalitas kembali dalam diri orang maupun anggota masyarakat. Fungsi penyembuhan dapat bersifat represif artinya bersifat menekan agar masalah sosial yang timbul tidak makin parah dan tidak menjalar.

2) Fungsi pencegahan (preventif). Dalam hal ini meliputi langkah-langkah untuk mencegah agar jangan sampai timbul masalah sosial yang baru, juga langkah-langkah untuk memelihara fungsionalitas seseorang maupun masyarakat.

3) Fungsi pengembangan (promotif, developmental). Untuk mengembangkan kemampuan orang maupun masyarakat agar dapat lebih meningkatkan fungsionalitas mereka sehingga hidup secara produktif.

4) Fungsi penunjang (suportif). Fungsi ini menopang usaha-usaha lain agar dapat lebih berkembang. Meliputi kegiatankegiatan yang dapat memperlancar keberhasilan program-program lainnya seperti bidang kesehatan, kependudukan dan keluarga berencana, pendidikan, pertanian, dan sebagainya.

Berbagai model penanganan pasien Skizofrenia telah dilakukan oleh para praktisi dalam rangka membantu pasien keluar dari permasalahannya. Model-model tersebut bervariasi antar profesi kesehatan seperti perawat, psikiater, psikolog, sosial worker yang sering bekerja untuk membantu pasien gangguan jiwa. Beberapa model yang diterapkan antara lain: psikoanalitik model, interpersonal, sosial, eksistensial, suportif dan medikal model (Stuart dan Laraia, 1998). Kognitif behavioral therapy (CBT) merupakan salah satu tindakan intervensi Pekerja Sosial untuk pasien Skizofrenia. Pekerja sosial dapat menggunakan cognitive behavior therapy dalam proses pemulihan orang dengan Skizofrenia. Kognitif behavior terapi membantu pasien diberbagai masalah kesulitan yang dialami seseorang dalam berbagai sisi kehidupan. Berbagai masalah gangguan jiwa juga sering memanfaatkan kognitif behavioral terapi baik digunakan secara tunggal maupun dikombinasikan dengan dengan psikofarmaka mapun terapi lain. Kognitif behavioral therapy (CBT) membantu individu untuk berkembang dengan meningkatkan ketrampilan dalam mekanisme koping menurunkan kecemasan dan meningkatkan hargadiri (Wheeler, 2008). 
Pekerja sosial bergerak dalam bidah kesehatan jiwa di berbagai seting, yaitu mental hospitals, halfway houses for the mentally ill, outpatient clinics dan treatment lain. Peran pekerja sosial dalam setting health care bidang kesehatan mental adalah berada di seting rumah sakit, keluarga, dan kesehatan umum. Peran pekerja sosial di seting rumah sakit adalah:

1) Mengasesmen psikologis dan lingkungan klien terkait kekuatan dan kelemahan

2) Berkolaborasi dengan tim disiplin lain terkait memaksimalkan layanan dari pelayanan medis.

3) Bekerja sama dengan keluarga dan mendukung treatment yang sedang dilakukan di rumah sakit oleh pengetahuan-pengetahuan yang kompleks,

4) Mengidentifikasi sumber-sumber yang bisa meningkatkan layanan dari interdisipliner.

5) Melayani sebagai broker dari layanan masyarakat menghubungkan kebutuhan klien dengan sumbersumber yang ada,

6) Berpartisipasi dalam proses pembuatan kebijakan,

7) Melihat penelitian-penelitian yang bisa didasarkan dari praktik kerja.

\section{METODE}

Artikel ini disusun dengan menggunakan kajian literatur dan dokumen, yaitu literatur barupa buku-buku, makalah ataupun jenis tulisan lainnya dan juga kajian terhadap berbagai macam dokumen yang terkait dengan topik intervensi pekerja sosial terhadap orang dengan Skizofrenia yang diangkat dalam artikel ini.

\section{PEMBAHASAN}

Skizofrenia adalah salah satu gangguan jiwa yang berat. Gangguan ini mempengaruhi sisi kognitif dan cara hidup realitas dalam kehidupan sehari-hari. Skizofrenia disebutkan bahwa gangguan yang tidak bisa sembuh dikarenakan kerusakan bagian otak, hanya bisa dipulihkan untuk bisa kembali ke kehidupan sosial.

Orang dengan Skizofrenia akan mengalami tiga simtom yaitu simtom positif, negatif, dan disorganisasi. Masing-masing dari simtom yang ada berbeda antara simtom satu sama lain, oleh karena itu seperti disebutkan bahwa Skizofrenia tidak memiliki ciri-ciri yang sama seperti gangguan lainnya. Bisa saja gejala orang dengan Skizofrenia satu dengan orang dengan Skizofrenia lain, bisa memiliki satu atau dua kesamaan, atau berbeda satu atau dua dari simtom.

Indonesia adalah negara berkembang, yang membutuhkan proses dalam pemenuhan kebutuhan masyarakatnya. Untuk masyarakat yang terkategori tak memiliki gangguan jiwa (atau sering disebut orang normal), kebutuhannya belum semua terpenuhi, juga terutama untuk orang-orang termajinalisasi seperti orang dengan Skizofrenia. Seperti data yang dikeluarkan oleh Riskesdas Tahun 2013, masyarakat Indonesi di pedesaan yang masih memperlakukan orang dengan Skizofrenia dengan cara dipasung. Cara yang penulis anggap bahwa tidak memanusiakan manusia. Faktor budaya dan religius di Indonesia sangat mempengaruhi bagaimana masyarakat berperilaku menghadapi orang dengan Skizofrenia tersebut, namun cara yang tepat atau intervensi dari masyarakat yang telah dilakukan perlu mendapat bantuan baik dari pemerintah atau stakeholder lain.

Skizofrenia sering mendapat stigma dari masyarakat adalah 'orang gila'. Hal ini menunjukan bahwa orang dengan Skizofrenia mendapatkan stigma negatif apabila klien kembali pada kehidupan masyarakat yang kemungkinan akan menghambat proses pembiasaan kembali ke masyarakat. Skizofrenia adalah salah satu jenis gangguan jiwa yang masih dalam perkembangan penelitian dalam proses intervensinya dan pemulihannya.

Salah satu intervensi teradap orang dengan Skizofrenia adalah rehabilitasi sosial, yaitu berupa upaya ditujukan untuk mengintegasikan kembali seseorang ke dalam 
kehidupan masyarakat dengan cara membantunya menyesuaikan diri dengan keluarga, masyarakat dan pekerjaan. Orang dengan Skizofrenia akan berintegrasi dengan masyarakat apabila memiliki kemampuan fisik, mental dan sosial serta diberikan kesempatan untuk berpartisipasi. Hal yang sama yang dilakukan dalam intervensi orang dengan Skizofrenia. Dengan adanya rehabilitasi sosial untuk orang dengan Skizofrenia, media untuk berfungsi kembali bisa bertahap berubah menjadi lebih baik lagi.

Rehabilitasi sosial membutuhkan profesi dengan multidisiplin untuk membantu orang dengan Skizofrenia. Pekerja sosial adalah salah satu profesi yang dibutuhkan untuk membantu tahap intervensi kepada orang dengan Skizofrenia. Psikiatri akan menganalisis gejala apa yang dihadapi oleh orang dengan Skizofrenia, lalu apa yang akan dilakukan oleh pekerja sosial?

Pekerja sosial memiliki peranan dalam hubungan interaksi yang dilakukan oleh orang dengan Skizofrenia, seperti dengan keluarga, teman, masyarakat. Seperti yang diungkapkan oleh Skidmore, dkk., bahwa terdapat upaya yang dilakukan untuk mendukung upaya layanan kesehatan jiwa, dari penyediaan layanan inpatient dan outpatient orang dengan gangguan jiwa, konsultasi, follow-up, dan lainlain. Pekerja sosial bisa bergabung dalam konsultasi yang berada dalam seting intervensi. Pekerja sosial juga bisa melakukan manajemen kasus yang dilakukan dengan profesi lain dan keluarga untuk menentukan cara dalam mengintervensi klien. Pekerja sosial melihat hubungan interaksional yang mempengaruhi kondisi klien. Oleh karena itu, bukan sekedar obat yang diberikan kepada orang dengan Skizofrenia, melainkan memperbaiki kondisi lingkungan sekitar klien tersebut. Apabila gejala tidak disembuhkan, mengapa tidak untuk memulihkan lingkungan sekitarnya? Karena dengan adanya intervensi dari Pekerja Sosial, upaya pemulihan lingkungan akan mencoba mendukung proses pemulihan Skizofrenia dalam pelaksanaannya.
Pekerja sosial dapat melakukan sesuatu hal yang dilakukan pada orang Skizofrenia dan lingkungannya, yaitu:

1) Mengasesmen psikologis dan lingkungan klien terkait kekuatan dan kelemahan

Hal ini bisa diasesmen dari pihak keluarga, teman dekat, masyarakat, bahkan diri orang dengan Skizofrenia sendiri.

2) Berkolaborasi dengan tim disiplin lain terkait memaksimalkan layanan dari pelayanan medis.

3) Bekerja sama dengan keluarga dan mendukung treatment yang sedang dilakukan di rumah sakit oleh pengetahuan-pengetahuan yang kompleks, hal ini adalah yang disebutkan sebelumnya upaya untuk penyelesaian perubahan lingkungan demi orang dengan Skizofrenia.

4) Mengidentifikasi sumber-sumber yang bisa meningkatkan layanan dari interdisipliner.

5) Melayani sebagai broker dari layanan masyarakat menghubungkan kebutuhan klien dengan sumbersumber yang ada, hubung interaksionis dengan masyarakat,

6) Berpartisipasi dalam proses pembuatan kebijakan,

7) Melihat penelitian-penelitian yang bisa didasarkan dari praktik kerja.

\section{Cognitive behavior therapy (CBT)} dapat meningkatkan harga diri pada kelompok intervensi lebih tinggi. Intervensi yang diberikan berupa perubahan perilaku dan kognitif yang menyebabkan perilaku. Pekerja sosial harus memiliki keterampilan ini dalam menangani orang dengan Skizofrenia. Orang dengan Skizofrenia adalah fenomena dengan adanya kemunduran aktifitas dalam menangani kehidupan (gejala negatif). Jika pekerja sosial memberikan intervensi kepada pasien dan keluarga pasien, dan pasien tidak mau melakukan proses intervensi tersebut, makan dibutuhkan metode kognitif dalam 
pelaksanaan kogntif tersebut. Dengan demikian pekerja sosial adalah salah satu profesi yang dibutuhkan dalam hubungan interaksionis,bahkan treatment dengan klien baik layanan secara langsung atau tidak langsung. Profesi yang dibutuhkan dalam kordinasi dalam intervensi orang dengan Skizofrenia adalah salah satunya pekerja sosial yang memandang dari hubungan interaksionis klien dengan lingkungannya.

\section{SIMPULAN}

Skizofrenia adalah gangguan jiwa berat yang membutuhkan treatment dalam proses pemulihannya. Banyak hal yang mempengaruhi stigma orang dengan Skizofrenia dari masyarakat. Intervensi yang diberikan melalui profesi multidisipliner.

CBT dapat menurunkan kecemasan, mekanisme koping, dan dapat meningkatkan harga diri pasien serta menangani orang dengan Skizofrenia. Dengan demikian pekerja sosial adalah salah satu profesi yang dibutuhkan dalam hubungan interaksionis, bahkan keterampilan treatment dengan klien baik layanan secara langsung atau tidak langsung. Profesi yang dibutuhkan dalam kordinasi dalam intervensi orang dengan Skizofrenia adalah salah satunya pekerja sosial yang memandang dari hubungan interaksionis klien dengan lingkungannya.

\section{DAFTAR PUSTAKA}

American Psychiatric Association. 2000. Diagnostic and Statiscal Manual of Mental Disorders, Fourth Edition Text Revision. Washington. Melalui, $<\mathrm{http}$ ://en.bookfi.org/> [08/10/15]

Chaplin, C.P. Kamus Lengkap Psikologi (Terj. Kartini Kartono; Jakarta: Rajawali Pers, 1989, hlm. 445).

Davison, Gerald C., Neale, John M., dan Kring, Ann M.. 2012. Psikologi Abnormal Edisi Ke-9. Jakarta: PT RajaGrafindo Persada. Penerjemah, Noermalasari Fajar.
Departemen Penelitian dan Pembangunan Indonesia. 2013. Melalui, $<$ http://litbang.depkes.go.id > [13/09/15]

Heller, Nina R., dan Glitterman, Alex. 2010. Mental Health and Social Problem: A Social Work Perspective. London, New York: Routledge Taylor \& Francis Group.

Kadir Ruslan. 16 Juni 2014. Artikel Kejiwaan, Fakta Menarik tentang Prevalensi Gangguan Jiwa di Indonesia. (diakses 21 September 2015). http://www.kompasiana.com/kadirsaja/f akta-menarik-tentang-prevalensiganggua n-jiwa-di-indonesia-diyogyakarta-palingtinggi 552923be6ea834e16a8b4569

Llyold, Chris. 2010. Rehabilitation Vocational and Mental Health. United Kingdom: Wiley Blalckwell.

Skidmore, Rex A., Thackeray, Milton G., dan Farley, O. William. 1994. Introduction to Social Work: Sixth Edition. United States of America: Prentice-Hall International, Inc.

Simanjuntak, Julianto. 2008. Konseling dan Gangguan Jiwa dan Okulitisme: Membedakan Gangguan Jiwa dan Kerasukan Setan. Jakarta: PT Gramedia Pustaka Utama.

Sumarnonugroho, T. 1987. Sistem Intervensi Kesejahteraan Sosial. Yogyakarta: PT. Hanindita.

Utomo, T. Laksono. 2013. Hubungan Antar Faktor Somatik, Psikososial, dan SosialKultur dengan Kejadian Skizofrenia di Instalasi Rawat Jalan RSJD Surakarta. Fakultas Ilmu Kesehatan, Universitas Muhammadiyah Surakarta. 